\title{
AVALIAÇÃO DA ATIVIDADE BACTERICIDA DE DESINFETANTES COMERCIAIS EM AMOSTRAS BACTERIANAS ISOLADAS DE BANHEIROS PÚBLICOS
}

\author{
Amanda Borges Collete ${ }^{1}$, Valeria Esmenio Silva ${ }^{1}$, Joyce Marinho Souza ${ }^{2}$, Marcus Vinícius Pimenta \\ Rodrigues $^{2}$ \\ Universidade do Oeste Paulista - UNOESTE, ${ }^{1}$ Curso de Química, ${ }^{2}$ Mestrado em Meio Ambiente e Desenvolvimento \\ Regional, Presidente Prudente, SP. e-mail: marcusvinicius@otmail.com
}

\begin{abstract}
RESUMO
A contaminação por microrganismos patogênicos pode estar relacionada com o contato com superfícies inanimadas como vasos sanitários. Diante dessa realidade, o presente estudo teve como objetivo avaliar a atividade bactericida de cinco desinfetantes comerciais (o-benzil pclorofenol 0,9\%, quaternário de amônio - 0,45\%; 0,30\%; 0,28\% e 0,25\%), contra bactérias isoladas de vasos sanitários públicos. As amostras foram coletadas por meio de Swabs e coradas pela coloração de Gram. Das amostras isoladas, E. coli, Proteus e Staphylococcus sp. foram escolhidas para os demais testes. Foram realizados testes de esterilidade dos desinfetantes utilizando os meios MacConkey e Muller-Hinton a fim de evitar resultados falso positivos. Os resultados mostraram que o princípio ativo a o-benzil p-clorofenol $0,9 \%$ obteve eficácia contra os três microrganismos, ao passo que o princípio ativo de quaternário de amônia, em diferentes concentrações foi eficaz contra algumas bactérias, com eficácia reduzida durante o período de 21 dias.
\end{abstract}

Palavras-chave: atividade bactericida, desinfecção, desinfetantes, princípio ativo, vasos sanitários.

\section{EVALUATION OF BACTERICIDAL ACTIVITY OF COMMERCIAL DISINFECTANTS ON BACTERIAL SAMPLES ISOLATED FROM PUBLIC TOILETS.}

\begin{abstract}
The contamination by pathogenic microorganisms can be related to contact with inanimate surfaces such as toilets. Given this reality, the present study aimed to evaluate the activity of commercial disinfectants 5 (the benzyl-p-chlorophenol $0.9 \%$ and ammonium quaternary $-0.45 \%$, $0.30 \%, 0.28 \%, 0.25 \%)$, against bacteria isolated from public toilets. The samples were collected with Swabs, and stained by Gram staining. Among the isolated samples Escherichia coli, Proteus and Staphylococcus sp were chosen to next tests. The sterility tests of disinfectants were performed on culture media MacConkey and Mueller-Hinton, avoiding false-positive results. The results showed that the active principle benzyl-p-chlorophenol obtained $0.9 \%$ efficacy against 3 microorganisms, while the active principle quaternary ammonia in different concentrations was effective against some bacteria, but with decrease of activity throughout the 21 day period.
\end{abstract}

Keywords: bactericidal activity, disinfection, disinfectant, active principle, toilet. 


\section{INTRODUÇÃO}

As bactérias fazem parte da microbiota normal do ser humano, colonizando principalmente pele, trato gastrointestinal, orofaringe e vagina ${ }^{1}$. Em sua grande maioria, não provocam doenças ao hospedeiro, mas podem desenvolver comportamento patogênico a medida que o ambiente se torna favorável a sua disseminação $^{2}$. Cerca de $20 \%$ dos constituintes de fezes humanas são bactérias, as mesmas são depositadas em vasos sanitários que, consequentemente, se tornam reservatórios desses microrganismos potencialmente patogênicos ${ }^{1}$.

A ação bactericida dos desinfetantes mais comumente utilizados para higienização de vasos sanitários está relacionada com princípios ativos compostos de quaternário de amônio (QACS) e derivados fenólicos (obenzil p-clorofenol). Esses princípios são capazes de inativar enzimas responsáveis por processos metabólicos de produção de energia, desnaturar proteínas celulares essenciais e romper a membrana celular das bactérias $^{3-5}$.

Considerados desinfetantes de baixa toxicidade e classificados de atividade de baixo nível, os QACs são efetivos contra bactérias Gram-positivas e apresentam menor atividade frente às bactérias Gram negativas. Não apresentam ação letal para esporos bacterianos, e para micobactérias, sendo $P$. aeruginosa, Escherichia coli e Salmonella typhimurium resistentes à sua ação $0^{6,7}$.

A ação bactericida dos compostos fenólicos depende da concentração em que o agente está presente em soluções ${ }^{8}$. Em concentrações ideais, os fenóis são considerados bactericidas e fungicidas de baixo custo sem possuir alta toxicidade ${ }^{9}$. Os compostos fenólicos apresentam alta capacidade de inibir o crescimento de cocos gram positivos como Staphylococcus aureus e bacilos gram negativos como Escherichia coli ${ }^{5,10}$, apresentando eficácia contraditória para diferentes espécies de fungos e vírus $5,11-13$

O sucesso da desinfecção, processo de diminuição/eliminação de microrganismos em superfícies abióticas, não depende somente do desinfetante de escolha, mas sim da concentração do princípio ativo, modo de uso, tempo de ação, sobre quais microrganismos atua e a natureza do material a ser desinfetado ${ }^{3}$.

O presente estudo teve como objetivo identificar as principais bactérias presentes em vasos sanitários públicos do município de Mirante do Paranapanema e avaliar a atividade antibacteriana dos principais desinfetantes comerciais de escolha. 


\section{MATERIAIS E MÉTODOS}

\section{Amostras microbiológicas}

As amostras microbiológicas foram coletadas de banheiros públicos, localizados na Praça Francisco Farias na cidade de Mirante do Paranapanema - SP, onde há grande fluxo de usuários, durante o mês de outubro de 2013. A coleta foi realizada durante 5 dias, em dois períodos 10:00 e 16:00 horas, das paredes dos vasos sanitários com um auxílio de um Swab estéril, evitando contato com a água, e encaminhadas imediatamente para o laboratório de Análises Clínicas Bioclínico para análise.

O Swab da amostra coletada foi armazenado em tubo contendo meio $\mathrm{BHI}$ e incubado por 24 horas a $37^{\circ} \mathrm{C}$, em seguida semeada em meio Ágar sangue e incubadas novamente por 24 horas a $37^{\circ} \mathrm{C}$. Foi realizada análise macroscópica das colônias crescidas e coloração de Gram para categorização de características morfotintoriais das bactérias isoladas.

\section{Testes bioquímicos}

Após categorização, as colônias foram semeadas em placas de Petri contendo meio de cultura indicados e submetidas a testes bioquímicos clássicos. Ágar MacConckey e Ágar sangue para bacilos Gram negativos; Ágar Sal Manitol e Ágar Sangue para cocos Gram positivos, e incubados a temperatura de $37^{\circ} \mathrm{C} \pm 1^{\circ} \mathrm{C}$ durante 24 horas.
Para bacilos gram negativos foram realizados os testes da urease, por meio de inoculação superficial da colônia em tubo contendo Uréia de Christensen e incubado por 24 horas a $35^{\circ} \mathrm{C}$, a coloração amarela do meio após incubação indicou presença de Escherichia coli, a mudança de coloração para vermelho indicou presença de Proteus; cultura em meio inclinado TSI (Tríplice Açúcar Ferro) para avaliar a fermentação da glicose, produção de gás e produção de $\mathrm{H}_{2} \mathrm{~S}$; prova da oxidase, realizada adicionando uma gota do composto tetrametil $p$-fenileno de amina em papel filtro apoiado em uma lamina e, em seguida, adicionada uma porção da colônia bacteriana com alça de platina. $\mathrm{O}$ desenvolvimento da cor púrpura no papel filtro em até 1 minuto indicou oxidase positiva; avaliação de degradação de citrato, realizada por semeadura em meio citrato de Simmons em tubo inclinado e incubado por 24 horas a $35^{\circ} \mathrm{C}$, a positividade foi verificada pela coloração azul do meio ${ }^{14}$.

Para cocos Gram positivos foram realizados os testes da catalase, no qual foi utilizada uma gota de solução aquosa de peróxido de hidrogênio a 3-5\% em lâmina microscópica e adicionado uma porção do crescimento bacteriano com alça de platina, a formação de bolhas indicou catalase positiva; DNAase por meio de cultura em meio Ágar DNAse (MBiolog Diagnósticos) e incubado a $35^{\circ} \mathrm{C}$ por 24 horas, a coloração 
rósea ao redor das colônias indicou DNAse positiva; coagulase em tubo, na qual foi realizada em tubo de ensaio contendo $0,5 \mathrm{ml}$ de plasma incubado por 1 hora, 4 horas e 24 horas a $35^{\circ} \mathrm{C}$, a formação de coagulo observado após inclinação suave do tubo indicou coagulase positiva ${ }^{14}$.

\section{Seleção de desinfetantes comerciais}

Os desinfetantes foram adquiridos no supermercado da cidade de Mirante do Paranapanema - SP, selecionando marcas comumente encontradas no mercado nacional, com diferentes agentes bactericidas, dentro dos prazos de validade, e estocadas em local adequado conforme recomendações do fabricante, conforme Tabela 1.

Tabela 1. Composição química dos desinfetantes avaliados.

\begin{tabular}{|c|c|c|c|c|}
\hline Produto & Princípio ativo e concentração & $\begin{array}{l}\text { Data de } \\
\text { Fabricação }\end{array}$ & $\begin{array}{l}\text { Data de } \\
\text { validade }\end{array}$ & Lote \\
\hline Desinfetante A & $\begin{array}{l}\text { 0,45\% de Cloreto de Cocobenzil } \\
\text { Aquil Dimetil Amonio, Cloreto } \\
\text { de Didecil Amônio }\end{array}$ & $14 / 05 / 2013$ & $14 / 05 / 2015$ & 13407 \\
\hline Desinfetante B & Cloreto de Benzalcônio - 0,28\% & $16 / 04 / 2013$ & $16 / 04 / 2015$ & 809 \\
\hline Desinfetante C & $0,9 \%$ de o-benzil p-clorofenol & $30 / 07 / 2013$ & $30 / 02 / 2014$ & 1033 \\
\hline Desinfetante D & $\begin{array}{c}\text { Cloreto de alquil dimetil benzil } \\
\text { amônio - } 0,30 \%\end{array}$ & $04 / 2013$ & $04 / 2015$ & E03 13/108 \\
\hline Desinfetante E & $\begin{array}{l}\text { Cloreto de didecil Dimetil } \\
\text { Amônio/Cloreto de Aquil Amido } \\
\text { Propil Dimetil Benzil Amônio } \\
\text { ( } 80 \% \text { de pureza) } 0,25 \%\end{array}$ & $10 / 2012$ & $10 / 2014$ & $002 / 12$ \\
\hline
\end{tabular}

\section{Esterilidade dos desinfetantes analisados}

O teste de esterilidade foi realizado com objetivo de excluir as amostras que apresentassem qualquer tipo de microrganismos, para evitar resultados falso positivos. A alíquota de $1,0 \mathrm{~mL}$ de cada produto foi colocada em $4,0 \mathrm{~mL}$ de Tryptic Soy Broth (TSB). Os tubos foram incubados por 24 horas a $37^{\circ} \mathrm{C}$ e após, semeados em Tryptic Soy ágar (TSA) e Ágar MacConkey
(MC). No primeiro dia da abertura dos frascos originais, foram realizados os testes de esterilidade dos produtos.

\section{Teste de atividade bactericida}

As amostras bacterianas isoladas dos vasos sanitários foram inoculadas em 3,0 mL de TSB (Difco) e incubadas a $37^{\circ} \mathrm{C}$ até atingirem 0 padrão de turbidez de 1,0 na Escala MacFarland $\left(10^{8} \quad \mathrm{UFC} / \mathrm{mL}\right)$. Uma 
alíquota de 0,2 $\mathrm{mL}$ dessa suspensão foi adicionada a $0,8 \mathrm{~mL}$ de soro fetal bovino utilizado, como matéria orgânica, sendo essa mistura adicionada a $4,0 \mathrm{~mL}$ dos desinfetantes de acordo com a diluição utilizada na higienização dos banheiros. Após a agitação manual durante um minuto os tubos foram deixados à temperatura ambiente durante 10 minutos, para ação do agente bactericida. Uma alíquota de 0,1 mL dessa mistura foi semeada na superfície de TSA com neutralizante tiossulfato de sódio $0,6 \%$. As placas foram incubadas durante 24 48 horas a $37^{\circ} \mathrm{C}^{15}$. Logo após foram feitas as contagens das colônias. Como controle negativo foi realizado teste com solução salina $0,85 \%$ na ausência de material orgânico. O experimento foi realizado em triplicata.

\section{Teste do desinfetante}

Paralelo à avaliação da atividade bactericida, foi realizada a análise da eficácia dos princípios ativos dos desinfetantes, uma vez que a alteração na concentração do princípio ativo pode interferir na atividade bactericida. No início do experimento foi coletada uma amostra de $150 \mathrm{~mL}$ de cada produto desinfetante e armazenada em frasco estéril, lacrado, e envolto com papel refletor de luz e calor. Estes frascos foram armazenados ao abrigo da luz e calor, para comparação com as amostras que permaneceram em seus frascos originais passíveis de manipulação periódica. Para efeito de entendimento, essa amostra foi denominada amostra fechada, e a amostra que permaneceu em frasco original, amostra aberta. Nos sétimo, décimo quarto e vigésimo primeiro dias foram realizados os testes de atividade bactericida dos produtos, para analisar a estabilidade e a atividade bactericida das amostras. Todos os experimentos foram efetuados em ambiente asséptico, para evitar contaminação por outros tipos de microrganismos.

\section{RESULTADOS}

\section{Amostras microbiológicas}

Após a realização das coletas, categorização e identificação, foram encontradas as bactérias Staphylococcus sp, Serratia, Proteus, Escherichia coli, Shigella, Enterobacter. Foram escolhidas Escherichia coli e Proteus como representantes de bactérias Gram negativas e Staphylococcus sp. como representante de bactérias Gram positivas.

\section{Esterilidade dos desinfetantes}

Constatou-se a presença de crescimento bacteriano em um dos produtos (desinfetante C), nos dois meios de cultura utilizados para o teste de esterilidade, conforme Tabela 2. 
Tabela 2. Esterilidade dos desinfetantes

\begin{tabular}{ccc}
\hline Desinfetante & MacConkey & Mueller-Hinton \\
\hline A & Negativo & Negativo \\
\hline B & Negativo & Negativo \\
\hline C & Crescimento confluente & Crescimento confluente \\
\hline D & Negativo & Negativo \\
\hline E & Negativo & Negativo \\
\hline
\end{tabular}

Foi adquirido um novo desinfetante $C$, ocorreu a substituição do desinfetante C, e realizado novo teste de esterilização, cujo resultado foi negativo para ambos os meios de cultura utilizados.

\section{Teste de eficácia da atividade bactericida}

O teste de eficácia da atividade bactericida, foi aplicado frente às bactérias Staphylococcus sp, Proteus e Escherichia coli, sendo observada a ausência ou a presença de crescimento, após a incubação, através da turvação do meio de cultura. Todos os testes foram feitos em triplicatas, apresentando normalidade nos resultados.

A eficácia bactericida frente aos microrganismos Staphylococcus sp, Proteus e Escherichia coli, nos $1^{\circ}, 7^{\circ}, 14^{\circ}$ e $21^{\circ}$ dias estão representadas na Tabela 3.
Nos Desinfetantes A, B, D e E, foram testadas concentrações diferentes de um mesmo princípio ativo (quaternário de amônio). Na tabela 3 pode-se verificar que, durante o período de avaliação do 1으, 7으, 14은 e 21 ำ dias, a maior concentração desse princípio ativo $0,45 \%$ (desinfetante A), inativou os 3 microrganismos expostos.

O desinfetante $B$, com $0,28 \%$ de quaternário de amônio, apresentou crescimento de quantidades de colônias de $\mathrm{E}$. coli, não sendo eficaz contra esse microrganismo. Frente a Proteus o crescimento foi confluente a partir do $21^{\circ}$ dia de exposição, o que sugere uma adaptação desse microrganismo. Houve um crescimento confluente de Staphylococcus sp. em todos os dias testados, sendo ineficaz contra o microrganismo. 
Tabela 3. Teste eficácia bactericida dos desinfetantes testados frente a Escherichia coli, Proteus e Staphylococcus sp.

\begin{tabular}{|c|c|c|c|c|c|c|}
\hline Microrganismo & $\begin{array}{l}\text { Tempo } \\
\text { de } \\
\text { contato } \\
\text { (dias) }\end{array}$ & $\begin{array}{c}\text { Desinfetante } \\
\text { A }\end{array}$ & $\begin{array}{c}\text { Desinfetante } \\
\text { B }\end{array}$ & $\begin{array}{c}\text { Desinfetante } \\
\text { C }\end{array}$ & $\begin{array}{c}\text { Desinfetante } \\
\text { D }\end{array}$ & $\begin{array}{c}\text { Desinfetante } \\
\text { E }\end{array}$ \\
\hline \multirow[t]{4}{*}{ Escherichia coli } & 10 & Negativo & 04 colônias & Negativo & Negativo & $\begin{array}{c}\text { Crescimento } \\
\text { confluente }\end{array}$ \\
\hline & 70 & Negativo & 04 colônias & Negativo & Negativo & $\begin{array}{c}\text { Crescimento } \\
\text { confluente }\end{array}$ \\
\hline & 140 & Negativo & 03 colônias & Negativo & Negativo & $\begin{array}{c}\text { Crescimento } \\
\text { confluente }\end{array}$ \\
\hline & 210 & Negativo & 06 colônias & Negativo & Negativo & $\begin{array}{c}\text { Crescimento } \\
\text { confluente }\end{array}$ \\
\hline \multirow[t]{4}{*}{ Proteus } & 10 & Negativo & Negativo & Negativo & 10 colônias & $\begin{array}{c}\text { Crescimento } \\
\text { confluente }\end{array}$ \\
\hline & 70 & Negativo & Negativo & Negativo & 12 colônias & $\begin{array}{c}\text { Crescimento } \\
\text { confluente }\end{array}$ \\
\hline & 140 & Negativo & Negativo & Negativo & 15 colônias & $\begin{array}{c}\text { Crescimento } \\
\text { confluente }\end{array}$ \\
\hline & 210 & Negativo & $\begin{array}{l}\text { Crescimento } \\
\text { confluente }\end{array}$ & Negativo & $\begin{array}{l}\text { Crescimento } \\
\text { confluente }\end{array}$ & $\begin{array}{c}\text { Crescimento } \\
\text { confluente }\end{array}$ \\
\hline \multirow[t]{4}{*}{$\begin{array}{c}\text { Staphylococcus } \\
\text { sp. }\end{array}$} & 10 & Negativo & $\begin{array}{l}\text { Crescimento } \\
\text { confluente }\end{array}$ & Negativo & $\begin{array}{l}\text { Crescimento } \\
\text { confluente }\end{array}$ & $\begin{array}{c}\text { Crescimento } \\
\text { confluente }\end{array}$ \\
\hline & 70 & Negativo & $\begin{array}{l}\text { Crescimento } \\
\text { confluente }\end{array}$ & Negativo & $\begin{array}{l}\text { Crescimento } \\
\text { confluente }\end{array}$ & $\begin{array}{c}\text { Crescimento } \\
\text { confluente }\end{array}$ \\
\hline & 140 & Negativo & $\begin{array}{l}\text { Crescimento } \\
\text { confluente }\end{array}$ & Negativo & $\begin{array}{l}\text { Crescimento } \\
\text { confluente }\end{array}$ & $\begin{array}{c}\text { Crescimento } \\
\text { confluente }\end{array}$ \\
\hline & 210 & Negativo & $\begin{array}{l}\text { Crescimento } \\
\text { confluente }\end{array}$ & Negativo & $\begin{array}{l}\text { Crescimento } \\
\text { confluente }\end{array}$ & $\begin{array}{c}\text { Crescimento } \\
\text { confluente }\end{array}$ \\
\hline
\end{tabular}

O desinfetante D 0,30\% obteve êxito para Escherichia coli em todos os dias testados. Contra Proteus a concentração foi ineficaz e o crescimento do microrganismo foi exponencial. Frente a Staphylococcus sp., a concentração não obteve sucesso na qual a bactéria apresentou um crescimento confluente.
$O$ desinfetante $E$ 0,25\%, com menor concentração de quaternário de amônio, não apresentou eficácia contra nenhum dos microrganismos testados.

O desinfetante $\mathrm{C}$, com princípio ativo 0,9\% de o-benzil p-clorofenol, foi eficaz contra todas as bactérias em todos os dias testados. 


\section{DISCUSSÕES}

A contaminação dos vasos sanitários nos locais públicos ocorre pela alta rotatividade de indivíduos que possibilita a deposição de diferentes microrganismos; por meio de condições favoráveis a sua sobrevivência; por adaptação de microrganismos resistentes a ação bactericida de desinfetantes e por características intrínsecas do próprio microrganismo. A lavagem e utilização correta de agentes bactericidas eficientes, com uso diário nos banheiros, pode exercer um importante papel na eliminação de microrganismos patogênicos ${ }^{16}$.

As bactérias isoladas nesta pesquisa foram reportadas em estudos prévios, não se limitando a vasos sanitários. Medeiros ${ }^{17}$, analisou a contaminação em 50 torneiras de banheiros públicos, das quais 12 (24\%) apresentaram coliformes termotolerantes (Escherichia coli). Em estudo sobre contaminação de escovas dentais, Ferreira ${ }^{18}$ demonstrou que em $70 \%$ dos utensílios avaliados houve crescimento bacteriano. Identificados como Escherichia coli, presente na maior parte das amostras, Klebisiella pneumoniae, Streptococcus pyogenes e Staphylococcus coagulase positiva.

A viabilidade das bactérias nas mais diferentes superfícies abióticas é explicada por pesquisadores, em análise experimental, como sendo influenciada por fluídos biológicos, como saliva e urina. Esses fluidos conferem condições favoráveis para a manutenção dos processos metabólicos das bactérias, viabilizando sua sobrevivência e facilitando sua disseminação ${ }^{19-21}$. Flores et al. $^{22}$, demonstrou que a colonização de microrganismos em diferentes superfícies de banheiros públicos está diretamente relacionada a microbiota humana, principalmente pele, o que favorece a disseminação dessas bactérias por contato direto com a superfície colonizada. Mori ${ }^{23}$, aponta a formação de biofilme por bactérias isoladas de vasos sanitários e o tratamento que deve ser realizado para uma eficaz ação bactericida de desinfetantes. Após 5 horas de exposição, apenas 1 dos 3 desinfetantes testados foi capaz de inativar $90 \%$ das amostras testadas. Corroborando para o fato de que a formação de biofilme induz a resistência bacteriana a desinfecção, dificultando a descontaminação ${ }^{24}$.

A partir dos resultados encontrados foi possível verificar que a ação bactericida de desinfetantes comerciais contra Escherichia coli, Proteus e Staphylococcus sp., podem ou não ser eficazes, dependendo da concentração do desinfetante utilizado, tempo de contato com o microrganismo, e manuseio diário por um certo período. Resultado que corrobora com a pesquisa de Braga $^{3}$, na qual desinfetantes, tendo como princípios ativos compostos fenólicos e 
quaternários de amônio, apresentaram variação na eficácia bactericida frente a amostras de $S$. aureus e $E$. coli a medida que a concentração, modo de uso e o tempo de ação eram alterados. Molina ${ }^{25}$ ainda, pesquisou a eficácia de desinfetantes Quaternário de amônio, Ácido paracético, Clorhexidina, Liodofor e Hipoclorito de sódio frente a polls de $E$. coli e $S$. aureus sobreviventes a higienização de equipamentos de matadouro-frigorífico. Todos os desinfetantes avaliados apresentaram capacidade para inativar as bactérias sobreviventes no matadouro frigorífico. Por outro lado, a simulação indica que a manipulação "in loco" dos fatores concentração, tempo de contato e matéria orgânica, entre outros, podem permitir a sobrevivência dos microrganismos no ambiente.

A perda da eficácia bactericida, do princípio ativo quaternário de amônio dos desinfetantes $B, D$ e $E$ pode estar relacionada ao fato de que esse composto é volátil e de fácil degradação, tanto em meio orgânico como em contato com o ar atmosférico. Diferentemente do desinfetante $C$ que possui o-benzil p-clorofenol 0,9\%, o qual é um composto de baixa solubilidade em água, o que favorece a manutenção de sua concentração inicial ${ }^{26}$. Stone et al. $^{26}$, apresentaram que mesmo utilizando princípios ativos diferentes não houve a completa eliminação dos microrganismos, e enfatizou que o processo de assepsia é importante para Staphylococcus aureus, Escherichia coli e Proteus vulgaris, uma vez que são potencialmente patogênicos.

Esses resultados precisam de estudos mais aprofundados para melhor avaliação das possíveis causas da perda da atividade bactericida, como por exemplo, teste de porcentagem da concentração do princípio ativo dos desinfetantes. A partir do presente estudo, foi possível observar que os princípios ativos Quaternário de amônio $0,45 \% ; \quad 0,28 \% ; \quad 0,30 \%$ e $\quad 0,25 \%$ respectivamente, e o-benzil p-clorofenol $0,9 \%$, apresentam perfis e concentrações distintas. Ambos apresentaram resultados diferentes na eliminação de microrganismos, após abertura do frasco no $1^{\circ}, 7^{\circ}, 14^{\circ}$ e $21^{\circ}$ dias. A presente pesquisa demonstrou que há necessidade de investigar a eficiência bactericida dos desinfetantes disponíveis no mercado, a fim de garantir a proteção esperada pelo consumidor.

\section{CONFLITO DE INTERESSE}

Os autores declaram não haver qualquer potencial conflito de interesse que possa interferir na imparcialidade deste trabalho científico. 


\section{REFERÊNCIAS}

1. Levinson W. Microbiologia Médica e Imunologia. 10th ed. Porto Alegre: Artmed; 2010.

2. Anderson MIP, Wagner $\mathrm{HL}$, Campos CEA. O impacto da MFC na saúde do Brasil. Rev Bras Med Família Comunidade. 2006;2(6):82-3.

3. Braga SMS, Furtado VCS, Furlan CM. Avaliação in vitro da eficácia bactericida de desinfetantes de uso geral frente a amostras de Staphylococcus aureus e Escherichia coli. Rev Científica FEPI. 2010;3(3):1-4.

4. Goddard PA, McCue KA. Phenolic Compounds. In: Block SS, editor. Disinfection, Sterilization, and Preservation. 5th ed. Philadelphia: Lippincott Williams \& Wilkins; 2001. p. 1481.

5. Mcdonnell G, Russell AD. Antiseptics and disinfectants: Activity, Action, and Resistance. Clin Microbiol Rev. 1999;12(1):147-79.

6. Sander JE, Hofacre $\mathrm{CL}$, Cheng $\mathrm{I}-\mathrm{H}$, Wyatt RD. Investigation of resistance of bacteria from commercial poultry sources to commercial disinfectants. Avian Dis. United States; 2002;46(4):997-1000.

http://dx.doi.org/10.1637/00052086(2002)046[0997:IOROBF]2.0.CO;2

7. Colla FL, Rodrigues LB, Dickel LB, Borsoi A, Nascimento VP, Santos LR. Avaliação in vitro de clorexidina, amônia quaternária e ácido peracético frente a amostras de Salmonella Heidelberg isoladas de abatedouro avícola em 2005 e 2009. Pesqui Vet Bras. 2012;32(4):289-92. http://dx.doi.org/10.1590/S0100-

736X2012000400003

8. Vaquero MJR, Alberto MR, Nadra MCM. Antibacterial effect of phenolic compounds from different wines. Food Control. 2007;18:93-101. http://dx.doi.org/10.1016/i.foodcont.2005.0 8.010

9. Quinn PJ, Markey BK. Disinfection and Disease Prevention in Veterinary Medicine. In: Block SS, editor. Disinfection, Sterilization, and Preservation [Internet]. 5th ed. Philadelphia: Lippincott Williams \& Wilkins; 2001. p. 1481. Available from: https://books.google.com.br/books?id=3fkPJ17_TYC

10. Aziz NH, Farag SE, Mousa LA, Abo-Zaid MA. Comparative antibacterial and antifungal effects of some phenolic compounds. Microbios England. 1998;93(374):43-54.

11. Rutala WA, Peacock JE, Gergen MF, Sobsey MD, Weber DJ. Efficacy of hospital germicides against adenovirus 8 , a common cause of epidemic keratoconjunctivitis in health care facilities. Antimicrob Agents Chemother. 2006;50(4):1419-24. http://dx.doi.org/10.1128/AAC.50.4.14191424.2006

12. Thevenin $T$, Lobert PE, Hober $D$. Inactivation of an enterovirus by airborne disinfectants. BMC Infect Dis. 2013;13:177. http://dx.doi.org/10.1186/1471-2334-13-177

13. Narang HK, Codd AA. Action of commonly used disinfectants against enteroviruses. J Hosp Infect England. 1983;4(2):209-12.

14. Brasil. Manual de Microbiologia Clínica para o Controle de Infecção Relacionada à Assistência à Saúde. Módulo 6: Detecção e identificação de bactérias de importância médica. Agencia Nacional de Vigilancia Sanitária - ANVISA. Brasília; 2013 p. 150.

15. Reis LM, Rabello BR, Ross C, Santos LMR. Avaliação da atividade antimicrobiana de antissépticos e desinfetantes utilizados em um serviço público de saúde. Rev Bras Enferm. 
http://dx.doi.org/10.1590/S0034$\underline{71672011000500011}$

16. Russell AD. Mechanisms of antimicrobial action of antiseptics and disinfectants: an increasingly important area of investigation. J Antimicrob Chemother. 2002;49:597-9.

http://dx.doi.org/10.1093/jac/49.4.597

17. Medeiros Jr. MC, Silveira GS, Pereira JBB, Chavasco JM, Chavasco JK. Verificação de contaminantes de natureza fecal na superfície de torneiras de banheiros públicos. Rev Univ Val Rio Verde. 2012;10:297-303. http://dx.doi.org/10.5892/ruvrv.2012.101.29 $\underline{7303}$

18. Ferreira CA, Savi GD, Panatto AP, Generoso S, Barichello T. Microbiological evaluation of bristles of frequently used toothbrushes Avaliação microbiológica das cerdas de escovas dentárias de uso frequente. Dent Press J Orthod. 2012;17(4):72-6.

http://dx.doi.org/10.1590/S2176-

$\underline{94512012000400016}$

19. Hirai Y. Survival of bacteria under dry conditions; from a viewpoint of nosocomial infection. J Hosp Infect England; 1991;19(3):191-200.

20. Huang R, Mehta S, Weed D, Price CS. Methicillin-resistant Staphylococcus aureus survival on hospital fomites. Infect Control Hosp Epidemiol. United States; 2006;27(11):1267-9.

21. Rossi D, Devienne KF, Raddi MSG. Influência de fluídos biológicos na sobrevivência de Staphylococcus aureus sobre diferentes superfícies secas. Rev Ciên Farm Básica Apl. 2008;29(2):211-4.

22. Flores $\mathrm{GE}$, Bates $\mathrm{ST}$, Knights $\mathrm{D}$, Lauber $\mathrm{CL}$, Stombaugh J, Knight $\mathrm{R}$ et al. Microbial biogeography of public restroom surfaces. PLOS

One. http://dx.doi.org/10.1371/journal.pone.0028 $\underline{132}$

23. Mori $M$, Gomi $M$, Matsumune $N$, Niizeki K, Sakagami Y. Biofilm-forming activity of bacteria isolated from toilet bowl biofilms and the bactericidal activity of disinfectants against the isolates. Biocontrol Sci Japan. 2013;18(3):129-35.

http://dx.doi.org/10.4265/bio.18.129

24. Bridier a., Briandet R, Thomas V, Dubois-Brissonnet F. Resistance of bacterial biofilms to disinfectants: a review. Biofouling. 2011;27:1017-32.

25. Molina PDS. Eficácia de desinfetantes frente bactérias sobreviventes a higienização de equipamentos em matadouro-frigorífico de bovinos. Universidade Federal do Rio Grande do Sul; 2006. p. 51.

26. Kich JD, Borowsky LM, Silva VS, Ramenzoni $\mathrm{M}$, Triques $\mathrm{N}$, Kooler $\mathrm{FL}$ et al. Avaliação da atividade antibacteriana de seis desinfetantes comerciais frente a amostras de Salmonella typhimurium isoladas de suínos. Acta Sci Vet [Internet]. 2004;32(1):339. Available from: http://www.lume.ufrgs.br/handle/10183/19 908

Recebido para publicação em 08/09/2014

Revisado em 25/03/2015

Aceito em 15/04/2015 